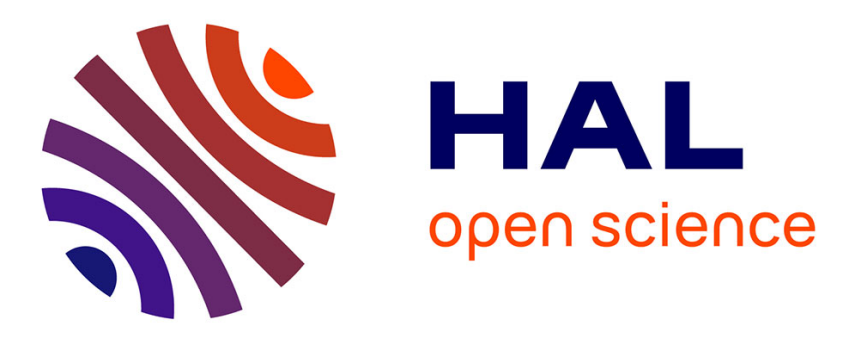

\title{
EPR study of Ti3+ ions formed under beta irradiation in silicate glasses.
}

Pierre Lombard, Nadège Ollier, Bruno Boizot

\section{To cite this version:}

Pierre Lombard, Nadège Ollier, Bruno Boizot. EPR study of Ti3+ ions formed under beta irradiation in silicate glasses.. Journal of Non-Crystalline Solids, 2011, 357 (7), pp.1685-1689. 10.1016/j.jnoncrysol.2010.12.015 . hal-00599077

\section{HAL Id: hal-00599077 \\ https://hal-polytechnique.archives-ouvertes.fr/hal-00599077}

Submitted on 8 Jun 2011

HAL is a multi-disciplinary open access archive for the deposit and dissemination of scientific research documents, whether they are published or not. The documents may come from teaching and research institutions in France or abroad, or from public or private research centers.
L'archive ouverte pluridisciplinaire HAL, est destinée au dépôt et à la diffusion de documents scientifiques de niveau recherche, publiés ou non, émanant des établissements d'enseignement et de recherche français ou étrangers, des laboratoires publics ou privés. 


\title{
EPR study of $\mathrm{Ti}^{3+}$ ions formed under beta irradiation in silicate glasses
}

\author{
P. Lombard ${ }^{1 *}$, N. Ollier ${ }^{1}$, B. Boizot ${ }^{1}$
}

1. Laboratoire des Solides Irradiés, UMR 7642 CEA-CNRS-Ecole Polytechnique Ecole Polytechnique, Route de Saclay, 91128 Palaiseau CEDEX, France

*Corresponding author: pierre.lombard@polytechnique.edu

Tél. : +33 (0) 169334502 - Fax. : +33 (0)1 69334654

Abstract: Reduction processes of $\mathrm{Ti}^{4+}$ ions in various silicate glasses have been studied by EPR spectroscopy at $20 \mathrm{~K}$. Different parameters like the $[\mathrm{Na}] /[\mathrm{Ti}]$ ratio, the integrated dose and $\mathrm{Ti}^{3+}$ ions ageing processes were analyzed in this work. Simulation of the $\mathrm{Ti}^{3+}$ ion EPR spectra in different Ti-doped silicate glasses has shown three different $\mathrm{Ti}^{3+}$ environment attributed to one ${ }^{[\mathrm{V}]} \mathrm{T} i^{3+}$ and two ${ }^{[\mathrm{V}]} \mathrm{Ti}^{3+}$ environment (square pyramid and trigonal bi-pyramid). The ${ }^{\left[\mathrm{Vl}^{2} \mathrm{Ti}^{3+}\right.}$ ion environment is observed only for $[\mathrm{Na}] /[\mathrm{Ti}]$ ratios higher or equal to 68 although the two others are observed for all values of the $[\mathrm{Na}] /[\mathrm{Ti}]$ ratio considered. In terms of relative proportions, the $\mathrm{Ti}^{3+}$ ions in a square pyramid of oxygen are the dominant species.

1. Introduction

Reduction processes of Rare Earth (RE) and Transition Metals (TM) ions in silicate and borosilicate oxide glasses under ionizing irradiation have been observed by Electron Paramagnetic Resonance (EPR) and luminescence spectroscopies in previous works. Ions like $\mathrm{Ti}^{4+}[1], \mathrm{Sm}^{3+}[2], \mathrm{Cr}^{3+}$ [3] or $\mathrm{Fe}^{3+}[4]$ are reduced as a function of the integrated dose and complete reduction of $\mathrm{Sm}^{3+}$ ions has been 
detected for integrated dose around $10^{9}$ Gy using luminescence measurements [2]. The reduction processes of ions in glasses can be associated to the production of electron hole pairs (excitons) in glasses. Some electrons can be trapped for example on the $\mathrm{Ti}^{4+}$ ions, leading to the formation of stable $\mathrm{Ti}^{3+}$ ions while holes are trapped by oxygen ions leading to the production of different punctual holes defects in the irradiated glass [5]. Moreover, for the highest doses integrated inside the glass $(\approx 1 \mathrm{x}$ $10^{9} \mathrm{~Gy}$ ), an increase of the network polymerization [6-11] associated with a production of molecular oxygen $[6,8-9,11]$ may occur. These two processes are correlated to the alkaline migration processes under ionizing radiation $[8,10]$. Efficiency of reduction processes under ionizing radiation should also depend on the environment around the doping ion in glasses.

Titanium ion is a good candidate for studying this relationship. First, when $\mathrm{TiO}_{2}$ is added to a glass composition, the main oxidation state in the matrix is the $\mathrm{Ti}^{4+}$ state $[12,13]$. Study of the titanium environment before irradiation will therefore bring information of the different environments around an oxidation state. The second reason is that titanium environment in glasses has been extensively studied by X-Ray Absorption Near Edge Structure (XANES), Extended X-ray Absorption Fine Structure (EXAFS) [12-18] and Raman spectroscopy [19, 20]. These works show the existence of different $\mathrm{Ti}^{4+}$ coordination number: ${ }^{[\mathrm{IV}]} \mathrm{Ti}^{4+},{ }^{[\mathrm{V}]} \mathrm{Ti}^{4+}$ and ${ }^{[\mathrm{V} V]} \mathrm{Ti}^{4+}$. The ${ }^{[\mathrm{IV}} \mathrm{T} \mathrm{T}^{4+}$ corresponds to a $\mathrm{Ti}^{4+}$ surrounded by a oxygen tetrahedron; the ${ }^{[\mathrm{V}]} \mathrm{Ti}^{4+}$ to a $\mathrm{Ti}^{4+}$ ion in a square pyramid of oxygen with one short titanyl $\mathrm{Ti}=\mathrm{O}$ bond $(1.7 \AA)$ and four longer $\mathrm{Ti}$ - O bonds $(1.93 \AA)$ [13]. The ${ }^{\left[{ }^{[V I}\right]} \mathrm{Ti}^{4+}$ is associated to an octahedral environment around $\mathrm{Ti}^{4+}$ ions $[12,13]$. The proportion between theses environments is mainly correlated to the content of network modifiers inside the glass [13-14, 17-19, 21]. In addition, alkaline ions act as charge compensator to stabilize $\mathrm{Ti}^{4+}$ ions in both five- 
and six-fold environment. Two reduction processes are therefore supposed to occur as a function of the integrated does. The first one is a reduction process from $\mathrm{Ti}^{4+}$ to $\mathrm{Ti}^{3+}$ ions without any coordination number changes for doses lower than $1 \times 10^{9} \mathrm{~Gy}$. The second one is associated to the alkaline migration at higher doses which could possibly leads to reduction processes of $\mathrm{Ti}^{4+}$ ions with a coordination number change. Under these assumptions and depending on the chemical composition of the glass, we shall observe in $\beta$-irradiated $\mathrm{SiO}_{2}-\mathrm{Na}_{2} \mathrm{O}-\mathrm{TiO}_{2}$ glasses three different environment for $\mathrm{Ti}^{3+}$ ions: ${ }^{\left[{ }^{[V}\right]} \mathrm{Ti}^{3+},{ }^{[\mathrm{V}]} \mathrm{Ti}^{3+}$ and ${ }^{[\mathrm{VI}]} \mathrm{Ti}^{3+}$.

The aim of this paper is to study the different environments of $\mathrm{Ti}^{3+}$ ions produced under $\beta$-irradiation in $\mathrm{SiO}_{2}-\mathrm{Na}_{2} \mathrm{O}-\mathrm{TiO}_{2}$ glasses with 1 to $4 \%$ mol. of titanium as a function of the alkaline content and of the integrated dose. The second goal is to correlate theses results on $\mathrm{Ti}^{3+}$ ions with literature results on $\mathrm{Ti}^{4+}$ environment as a function of the silicate glasses composition.

For that purpose, we have mainly used the X-band Electron Paramagnetic Resonance (EPR) spectroscopy at low temperature $(20 \mathrm{~K})$ associated with the simulation of experimental $\mathrm{Ti}^{3+}$ ions EPR spectra. This approach allows us to determine the EPR parameters ( $g$-tensor, widths) for each $\mathrm{Ti}^{3+}$ ion sites produced under ionizing radiation and their relative proportions as the function of the glass compositions and integrated doses.

\section{Experimental}

\subsection{Sample Preparation}

The different glass composition were prepared by mixing appropriate amounts of analytical reagent grade $\left(\mathrm{SiO}_{2}, \mathrm{TiO}_{2}, \mathrm{Na}_{2} \mathrm{CO}_{3}\right)$ in an agate mortar with ethanol. The powders were then transferred in a Pt-crucible and placed in an air-oven at $850^{\circ} \mathrm{C}$ for 
$10 \mathrm{~h}$. This temperature step was used to ensure a correct decarbonatation of the powders. After decarbonatation, the melt was heated to $1600^{\circ} \mathrm{C}$ in $3 \mathrm{~h}$ and quenched. The obtained samples were cut and manually polished on a Labram HR Mecapol. The different glasses studied in this work are presented in table 1 where the sample number corresponds to the $[\mathrm{Na}] /[\mathrm{Ti}]$ ratio of the silicate composition. The $\mathrm{S} 10$ $([\mathrm{Na}] /[\mathrm{Ti}]=10), \mathrm{S} 20([\mathrm{Na}] /[\mathrm{Ti}]=20)$ and $\mathrm{S} 68([\mathrm{Na}] /[\mathrm{Ti}]=68)$ samples are of the same composition than samples already studied by XANES and micro-Raman spectroscopy in previous works (resp. in [21] for S10 and S20 and [19] for S68).

All the samples were $\beta$-irradiated on a Van de Graaff accelerator (LSI, Ecole Polytechnique, France) with a $10 \mu \mathrm{A}$ current and an energy of $2.5 \mathrm{MeV}$ at different doses: $3.24 \times 10^{6} ; 3.23 \times 10^{7} ; 2.75 \times 10^{8} ; 5.53 \times 10^{8}$ and $1.68 \times 10^{9}$ Gy. During irradiation, the sample temperature never exceeded $80^{\circ} \mathrm{C}$.

All the samples were synthesized using the same protocol but the theoretical compositions has not been confirmed by a chemical analysis. Thus, we'll assume that the composition of all samples is affected by the same error.

\subsection{Experimental EPR spectroscopy}

X-band $(v=9.490 \mathrm{GHz})$ EPR spectra were recorded at $20 \mathrm{~K}$ using an OXFORD He cryostat on a EMX Bruker spectrometer. The microwave power used, $0.05 \mathrm{~mW}$, were determined by considering the saturation properties of $\mathrm{Ti}^{3+} \mathrm{EPR}$ lines at $20 \mathrm{~K}$. The different EPR spectra presented in this paper have been normalized to the same receiver gain $\left(1.10^{4}\right)$ and sample weight $(100 \mathrm{mg})$ in order to get quantitative comparison of the EPR lines intensities between the different samples. We emphasize that EPR spectroscopy is a tool where the absorbance spectra (i.e. the experimental spectrum integrated twice) of all EPR lines corresponding to one 
paramagnetic ion in a specific site can be correlated to the paramagnetic specie spin content inside the sample [22]. However, due to different saturation properties, the EPR linewidths of known EPR reference spectra (e.g. DPPH, strong and weak pitch) and $\mathrm{Ti}^{3+}$ EPR spectra are strongly different. In the present work it is thus very difficult to compare theses spectra to determine the absolute number of $\mathrm{Ti}^{3+}$ spins. Then, in this study, we will only use arbitrary units (a.u.) to analyze the evolution of $\mathrm{Ti}^{3+}$ ions content as a function of the integrated dose and silicate glass compositions. However, using simulation of EPR spectra (see §2.3), we are able to separate the experimental spectrum into a sum of $\mathrm{Ti}^{3+}$ elementary spectra corresponding to different sites of $\mathrm{Ti}^{3+}$ ions. In this case, the relative proportion of $\mathrm{Ti}^{3+}$ in each site, expressed in \%, will be determined by computing the ratio of the area under each elementary absorbance spectrum and the area under the total simulated spectrum.

Many different phenomena may induce an error on the measured values: position of the sample into the EPR cavity, variation of temperature, etc. The global error on each point of the EPR spectrum is estimated to be $4.8 \%$. This value was obtained by recording ten times the EPR spectrum of the same sample ( $S 80$ irradiated at 3,27 $\mathrm{x}$ $\left.10^{7} \mathrm{~Gy}\right)$. Each time the sample is removed and replaced into the EPR cavity and the temperature returns to ambient before decreased again.

\subsection{Simulation of EPR spectra}

Simulation of EPR spectra were realized using the ZFSFIT program developed by G. Morin and D. Bonnin [23]. This program was specially developed for fitting EPR powder spectra with paramagnetic species with nuclear spin I $\leq 7 / 2$ and electronic spin $S \leq 5 / 2$. The more general spin Hamiltonian calculated by ZFSFIT is:

$$
\beta H \cdot g \cdot S+\sum_{k=2,4 q=-k}^{+k} B_{k}^{q} O_{k}^{q}+S \cdot A \cdot I
$$


Where $\beta$ is the Bohr magnetron, $\mathrm{H}$ is the magnetic field tensor, $g$ is the Lande tensor, $S$ the spin tensor, $O_{k}^{\mp q}$ the Stevens operators, $B_{k}^{\mp q}$ the constant associated with the Stevens operators, $A$ the hyperfine tensor and $I$ the nuclear spin operator [23]. For trivalent titanium ions, $S=1 / 2$ and $I=0$. Therefore, the spin Hamiltonian used in our simulations is:

$$
\beta H \cdot g \cdot S
$$

Because we observe different $\mathrm{Ti}^{3+}$ EPR sites in our glasses, the simulated spectra calculated by ZFSFIT is the sum of the elementary spectrum of $\mathrm{Ti}^{3+}$ ions in each of theses sites. ZFSFIT compares the calculated spectrum with the experimental one, compute the difference between both and refine the given parameters ( $g$ values, isotropic width $\left(s_{0}\right)$, and anisotropic widths $\left(s_{1}, s_{2}\right.$ and $\left.s_{3}\right)$ for each $\mathrm{Ti}^{3+}$ ion EPR site) by a routine based on the Levenberg-Marquardt algorithm.

At the end of the fitting procedure, the obtained simulated EPR spectra for each $\mathrm{Ti}^{3+}$ environment are defined by three $g$-values which can be associated to the EPR axis of the system [24]. Because we are working with amorphous materials, our EPR spectra are the sum over all spatial orientations of the $\mathrm{Ti}^{3+}$ EPR spectrum and thus, it is impossible to associate a $g$ value with a spatial direction into the sample. By convention, we will assume that $g_{3} \geq g_{2} \geq g_{1}$. The three anisotropic widths $s_{1}, s_{2}$ and $s_{3}$ widths correspond to the $g$-strain process in amorphous material associated with $g$ values distribution. The $g$-strain process in the ZFSFIT program is treated as a perturbation of the Zeeman Hamiltonian term different along the $g$ tensor direction. By convention, we will assume $s_{3}=0$ to precisely quantify the other widths.

3. Results

\subsection{Influence of $[\mathrm{Na}] /[\mathrm{Ti}]$ ratio}


The figure 1 presents the EPR spectra of titanium-doped silicate glasses samples $\mathrm{S} 10$ to $\mathrm{S} 80$ after $\beta$-irradiation at $3.23 \times 10^{7}$ Gy. These spectra are complex and may be separated into two groups of lines. The first group, centered around $g=2.0076 \pm$ 0.003 and close to the $g$-value of free electron $\left(g_{e}=2.0023\right.$ [22]) is attributed to the paramagnetic hole defects created by irradiation [7,5] and the second group, centered around $g=1.935 \pm 0.003$ is attributed to $\mathrm{Ti}^{3+}$ ions [22, 25, 26]. In this paper we will mainly focus our study on the EPR spectrum of $\mathrm{Ti}^{3+}$ ions. Fig. 1 clearly shows a dependence between the shape of the $\mathrm{Ti}^{3+}$ EPR spectra and the $[\mathrm{Na}] /[\mathrm{Ti}]$ ratio. For a ratio less than 40, all the EPR spectra are identical and are characterized by a positive component at $g=1.935 \pm 0.003$ and a large negative component around $g \approx$ 1.855. When the $[\mathrm{Na}] /[\mathrm{Ti}]$ ratio increases to 80 , the EPR spectra shows an additional line determined by an intense positive peak at $g=1.963 \pm 0.003$ and a negative shoulder at $g=1.935 \pm 0.003$. Considering the existence of different EPR lines on the $\mathrm{Ti}^{3+}$ EPR spectra, we can conclude first that the $\mathrm{Ti}^{3+}$ EPR signal of these irradiated silicate glasses is the sum of different components corresponding to, at least, two different $\mathrm{Ti}^{3+}$ EPR sites. The first $\mathrm{Ti}^{3+}$ site in silicate glasses, hereafter

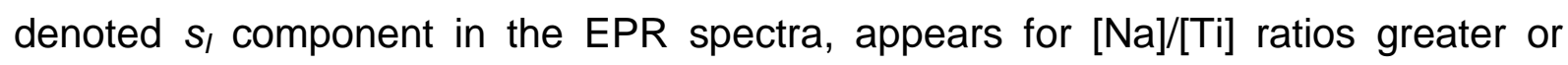
equal to 68 and can be determined by $g_{/ /} \approx 1.963$ and $g_{\perp} \approx 1.855$ axial symmetry. The second component in the $\mathrm{Ti}^{3+}$ EPR spectra is observed for all $[\mathrm{Na}] /[\mathrm{Ti}]$ ratios. However, we will show later that this EPR line is in fact the sum of two different components denoted $s_{\mid /}$and $s_{\mid I /}$ corresponding to two other $\mathrm{Ti}^{3+}$ environments in the irradiated silicate glasses.

\subsection{Influence of total integrated dose}


Figure 2 shows the EPR spectra of the two titanium doped silicate glasses S20 and S80 irradiated at different doses between $3.24 \times 10^{6}$ and $1.68 \times 10^{9}$ Gy. The EPR spectra of pristine S20 and S80 samples also presented in Fig. 2 don't show any signal in the region of $\mathrm{Ti}^{3+}$ EPR lines. We can conclude therefore that $\mathrm{Ti}^{3+}$ ions for these silicate glass compositions are only produced during irradiation and not during the glass synthesis. For the $S 20$ sample $([\mathrm{Na}] /[\mathrm{Ti}]=20)$, we observe an increase of the $\mathrm{Ti}^{3+} \mathrm{EPR}$ lines intensity corresponding to an increase of the $\mathrm{Ti}^{3+}$ content as a function of the dose integrated in the glass. We can also analyze the appearance of a shoulder at $g=1.963 \pm 0.003$ and a shift of the minimum of the EPR signal from $g=$ $1.846 \pm 0.003$ to $g=1.871 \pm 0.003$. According to our previous results, we can correlate these changes in the $\mathrm{Ti}^{3+}$ EPR spectra to a modification of the relative proportion of $\mathrm{Ti}^{3+}$ ions between the $s_{\mid l}$ and $s_{|l|}$ sites when the integrated dose increases. We can then attribute the $s_{\| /}$component EPR spectrum to the shoulder at $g=1.963$ and the minimum at $g=1.871$. Finally, the last $\mathrm{Ti}^{3+}$ environment characterized by the $s_{\text {III }}$ component has an EPR spectrum close to the EPR spectra observed for the lowest dose (3.24 x $\left.10^{6} \mathrm{~Gy}\right)$.

For the $\mathrm{S} 80$ sample, we observe also an increase of the $\mathrm{Ti}^{3+}$ EPR spectrum intensity with the integrated dose inside the silicate glass correlated with the increase of $\mathrm{Ti}^{3+}$ ions content. We can also see on Fig. 2 an increase of the relative intensity of $g=$ $1.935 \pm 0.003$ component and a displacement of the minimum of the signal from $g=$ $1.855 \pm 0.003$ to $g=1.868 \pm 0.003$ for integrated dose in silicate glasses higher than $5.58 \times 10^{8} \mathrm{~Gy}$. This result can be correlated to a decrease of the number of $\mathrm{Ti}^{3+}$ ions in the $s_{\text {/ site }}\left(g_{/ / /} \approx 1.963\right.$ and $\left.g_{\perp} \approx 1.855\right)$ when the integrated dose is in the order of the giga-gray. At these higher integrated doses, migration of alkaline ions under ionizing radiation has been observed $[8,10]$. The decrease of the $s$, component could 
be correlated to the migration of alkaline ion acting as charge compensator of the $\mathrm{Ti}^{3+}$ ions in this environment. Thus, this result could imply that the coordination number of $\mathrm{Ti}^{3+}$ ion in $s_{/}$site is greater than the coordination number of both $\mathrm{Ti}^{3+}$ in $s_{\| /}$and $s_{\| I I}$ sites.

\subsection{Post irradiation ageing processes.}

The figure 3 presents the EPR spectra of the S20 and S80 samples recorded just after their $\beta$-irradiation at $3.23 \times 10^{7}$ Gy and 165 days later. No significant changes are analyzed on the EPR spectra of the S20 sample as a function of the ageing time. By contrary for the $\mathrm{S} 80$ sample, we observe an important modification of the $\mathrm{Ti}^{3+}$ EPR signal mainly correlated to the intensity decrease of the $s_{\text {/ component. The }}$ glass sample ageing is also associated to a visible leaching of the S80 surface sample. Glass corrosion by water leads to three different kinds of process [27, 28]: hydration, hydrolysis and ionic exchange. In particular, ionic exchange between $\mathrm{Na}^{+}$ and $\mathrm{H}^{+}$ions during ageing processes lead to a decrease of the charge compensation intensity around $\mathrm{Ti}$ ions and thus, to a reorganization of $\mathrm{Ti}^{3+}$ environment. In the present case, we interpret this reorganization as a decrease of the coordination number around $\mathrm{Ti}^{3+}$. The similarities between the evolutions of the EPR spectrum of Ti doped silicate glass irradiated at high-dose (close or higher to $1 \times 10^{9} \mathrm{~Gy}$ ) showed on figure 2 and after a 165 days ageing presented on figure 3 confirm that the $s_{\text {/ site }}$ of $\mathrm{Ti}^{3+}$ ions has a higher coordination number than the other $\mathrm{Ti}^{3+}$ sites in the irradiated silicate glasses studied in this work.

\subsection{Simulation of experimental $\mathrm{Ti}^{3+}$ EPR spectra}


Using our previous observations on figures 1-3, we tried to reproduce the experimental EPR spectra of all our samples $\beta$-irradiated at different doses between $3.24 \times 10^{6}$ and $1.68 \times 10^{9}$ Gy. To determine the EPR parameters of the $s_{\text {I }}$ site, we substract the EPR spectra obtained 165 days after irradiation to the EPR spectra recorded just after irradiation. For the other sites, we tried different assumptions and we only kept the solution which reproduce the better all our EPR spectra. We conclude to the existence of three different EPR sites of $\mathrm{Ti}^{3+}$ determined by the EPR parameters given in table 2. Figure 4 shows for example the experimental $\mathrm{X}$-band EPR spectrum, the three $s_{l}, s_{\| /}$and $s_{|l|}$ components used to obtain the simulated spectrum and the total simulated spectrum defined by the sum of the $s_{l,} s_{\|}$and $s_{I I I}$ components for the $\mathrm{S} 80$ sample.

The obtained $s_{l}, s_{\|}$and $s_{\| /}$EPR spectra are very close to some results already reported in previous studies. For example, S. Arafa and F. Assagbhy [26] observed in X-irradiated $\mathrm{SiO}_{2}-\mathrm{Na}_{2} \mathrm{O}-\mathrm{TiO}_{2}$ glasses an EPR spectrum characterized by $g_{\perp}=$ 1.9693 and $g_{/ /}=1.9413$ very similar to our $\underline{s}_{l}$ spectrum. H. Böhm and G. Bayer [29] also obtained a similar spectrum defined by $g_{\perp}=1.970$ and $g_{/ /}=1.930$ by studying the ${ }^{[\mathrm{VI}]} \mathrm{Ti}^{3+}$ formed under reducing atmosphere in $\mathrm{Mg}_{2} \mathrm{TiO}_{4}$ crystals. V. Laguta et al. [30] reported the EPR spectrum of $\mathrm{Ti}^{3+}$ ions surrounded by five oxygen atoms and one oxygen vacancy in $\mathrm{PbTiO}_{3}$ crystals. Their spectrum, characterized by $g_{1}=1.965$; $g_{2}=1.919$ and $g_{3}=1.848$ is very close to our $s_{/ /}$spectrum. And $\mathrm{H}$. Böhm and G. Bayer [29], also published the EPR spectrum of $\mathrm{Ti}^{3+}$ in $\mathrm{La}_{2} \mathrm{TiO}_{5}$ crystals which is close to our $s_{\text {III }}$ spectrum. All theses previous studies supports the simulation solution we've kept. However the shape of the simulated EPR spectra will be discussed in section 4 .

\subsection{Proportions of $\mathrm{Ti}^{3+}$ ions in each site}


By a double integration of the simulated EPR spectra, we can obtain the proportion of $\mathrm{Ti}^{3+}$ ions in each titanium site inside the glass. Figure 5 presents the evolution of the mean proportion over all samples of $\mathrm{Ti}^{3+}$ ions in each site as a function of the total integrated dose (in log. scale). According to this figure, the $\mathrm{Ti}^{3+}$ ions produced during ionizing radiation in the silicate glasses are mainly in the $s_{\| I}$ site followed by the $s_{\|}$ site and finally the $s$, site which is only observed in the S68 and S80 samples.

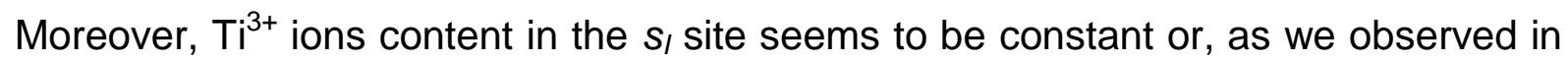
figure 2, decreases when the dose is close or higher than the giga-gray. As we already said, some of our samples have the same chemical composition as samples already studied in previous works. First of all, N. Ollier et al. [1] showed by XANES spectroscopy the existence of a mixture of ${ }^{[\mathrm{V}]} \mathrm{Ti}^{4+}$ and ${ }^{[\mathrm{VI}]} \mathrm{Ti}^{4+}$ in a sample very close to our S68 sample but with a [Na]/[Ti] ratio equals to 66 . More precisely, in his XANES spectroscopy study [21], F. Farges concludes to the existence in the S10 sample of $80 \%$ of ${ }^{[\mathrm{V}]} \mathrm{Ti}^{4+}$ and $20 \%$ of ${ }^{[\mathrm{VII}} \mathrm{Ti}^{4+}$. Depending on the total integrated dose, we observe in the $\mathrm{S} 10$ sample from 20 to $30 \%$ of $\mathrm{Ti}^{3+}$ ions in the $s_{\| /}$site and from 70 to 80 of $\mathrm{Ti}^{3+}$ ions in the $s_{\text {III }}$ site. In the case of the S20 sample, F. Farges concluded to

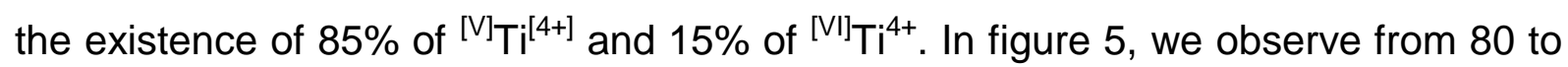
$90 \%$ of $\mathrm{Ti}^{3+}$ ions in the $s_{\| / I}$ site and from 10 to $20 \%$ of $\mathrm{Ti}^{3+}$ ions in the $s_{\| /}$site. With the assumption of a direct reduction from $\mathrm{Ti}^{4+}$ to $\mathrm{Ti}^{3+}$ for doses lower than $1 \times 10^{9} \mathrm{~Gy}$, we must emphasize the similarities between 1) the quantities of ${ }^{[\mathrm{V}]} \mathrm{Ti}^{4+}$ and the quantities of $\mathrm{Ti}^{3+}$ ions in the $s_{I I I}$ site and 2) the quantities of ${ }^{[\mathrm{VI}]} \mathrm{Ti}^{4+}$ and the quantities of $\mathrm{Ti}^{3+}$ ions in the $s_{\| /}$site. Then, we conclude that the $\mathrm{Ti}^{3+}$ ions in the $s_{|l|}$ site comes from the reduction of ${ }^{[V]} \mathrm{Ti}^{4+}$ ions and the $\mathrm{Ti}^{3+}$ ions in the $s_{/ /}$comes from the reduction of ${ }^{[\mathrm{VI}]} \mathrm{Ti}^{4+}$ ions. The question of the reduction efficiency will be discussed in the next section. 


\section{Discussion}

Previous works in literature have mainly concluded to the presence in glasses of $\mathrm{Ti}^{3+}$ ion in an octahedral environment even if authors observe large differences in $g$ tensor values derived from the studies. For example, Y. Kim and P. Bray analyzed in $\gamma$-irradiated $\mathrm{K}_{2} \mathrm{O}-\mathrm{TiO}_{2}$ glasses [31] an ${ }^{[\mathrm{VI}]} \mathrm{Ti}^{3+}$ EPR spectrum characterized by $g_{\perp}=$ 1.975 and $g_{/ /}=1.890$. S. Arafa and A. Bishay [32] attributed also to ${ }^{[\mathrm{VI}]} \mathrm{Ti}^{3+}$ a very symmetric $\mathrm{Ti}^{3+}$ EPR spectrum characterized by $g \approx 1.942$ in $\gamma$-irradiated $\mathrm{B}_{2} \mathrm{O}_{3}-\mathrm{CaO}$ $-\mathrm{TiO}_{2}$ glasses. However, our EPR results suggest the existence of different $\mathrm{Ti}^{3+}$ sites relative to different coordination numbers for $\mathrm{Ti}^{3+}$ ions. As shown in $\S 3.2$, the modifications of the EPR spectrum for the samples irradiated at the highest doses suggest a relation between the existence of $\mathrm{Ti}^{3+}$ ions in the $s_{/}$site and the number of sodium ions available for charge compensation. This is confirmed by the fact that we observe this site only on the EPR spectra of the samples with the highest $[\mathrm{Na}] /[\mathrm{Ti}]$ ratio (e.g. S68 and S80) and by the lower stability of this site during leaching (§ 3.4).

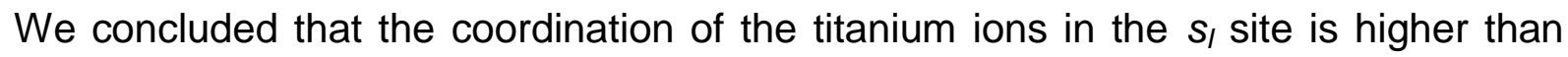
the coordination of $\mathrm{Ti}^{3+}$ ions in the $s_{\| /}$and $s_{\| /}$sites. To our knowledge, the higher observed coordination number for $\mathrm{Ti}^{3+}$ ions is VI. Thus, we attribute the $s_{\text {, site }}$ to ${ }^{[\mathrm{VI}]} \mathrm{Ti}^{3+}$ ions.

F. Farges [21] has proposed a possible square based pyramidal environment $\left({ }^{[\mathrm{V}]} \mathrm{Ti}^{4+}\right)$ in silicate glasses. In this coordination number $[13,16,21]$, the ${ }^{[\mathrm{V}]} \mathrm{Ti}^{4+}$ ions environment is characterized by one $\mathrm{Ti}=\mathrm{O}$ titanyl bond and four $\mathrm{Ti}-\mathrm{O}$ bonds. The assumption of a direct reduction processes for $\mathrm{Ti}$ doped silicate glasses studied in this work suppose production of ${ }^{[V} \mathrm{Ti}^{3+}$ ions in this square pyramidal environment. This particular stronger titanyl bond will influence strongly the powder EPR spectrum 
linewidth of this $\mathrm{Ti}^{3+}$ site. The width of $\mathrm{Ti}^{3+} \mathrm{EPR}$ line may be understood as the result of a $g$-strain process (i.e. a distribution of the $g$-values) [24]. This distribution traduces the variation of the environment of the paramagnetic ion along specific directions of the $g$ tensor. Thus, we could therefore correlate the particular shape of the $s_{\text {III }}$ EPR spectrum (Table 2, Fig. 4) characterized by a small width $\left(0.00515 \mathrm{~cm}^{-1}\right)$ for the $\mathrm{g}_{z}$ component of the $\mathrm{Ti}^{3+}$ powder spectrum in comparison to the $\mathrm{g}_{\mathrm{y}}\left(0.06273 \mathrm{~cm}^{-1}\right)$ and $g_{x}\left(0.13127 \mathrm{~cm}^{-1}\right)$ width values to ${ }^{[V]} \mathrm{Ti}^{3+}$ ions in square base pyramidal environment. Moreover, ${ }^{[\mathrm{V}]} \mathrm{Ti}^{3+}$ ions were already observed in some previous studies, for example by M. Nolan et al. [33] in non-stoechiometric $\mathrm{TiO}_{2}$ rutile.

The site $s_{/ /}$is more difficult to associate with a coordination number around $\mathrm{Ti}^{3+}$ ions. As we said it, we concluded that the coordination number associated to $s_{l}$ is higher than the coordination number associated to the $s_{/ /}$site. However, we observed by studying the proportions of $\mathrm{Ti}^{3+}$ in each site (§ 3.5) that $s_{/ /}$may correspond to a coordination number of VI. To explain this apparent discrepancy of our results, we propose to associate the $s_{\| /}$site of $\mathrm{Ti}^{3+}$ with a coordination number of $\mathrm{V}$ in a trigonal bi-pyramid shape (i.e. an octahedron with an oxygen vacancy). Such geometry was for example already observed for $\mathrm{Ti}^{4+}$ in $\mathrm{La}_{2} \mathrm{TiO}_{5}$ crystals and it is consistent with the EPR results of V. Laguta et al. [30]. F. Farges [20] didn't take into account this geometry in his XANES study because it is less common to observe $\mathrm{Ti}^{4+}$ in trigonal bi-pyramide than in square pyramid. Moreover, his results are defined with $a \pm 10 \%$ error. Thus, we can assume that the trigonal bi pyramid geometry is an intermediary case between the octahedron and the square pyramid which was not taken into account in the previous studies. This may explain the apparent discrepancy between our results. However, because figure 5 shows different slopes of reduction, it may exist in our samples some different reduction efficiency, depending on the titanium 
sites and on the integrated dose. This different reduction efficiency may change our result, especially concerning the total $\mathrm{Ti}^{3+}$ ions quantities. This problem must be taken into account for our next studies.

\section{Conclusion}

We studied in this work by X-band EPR spectroscopy and simulation of EPR spectra the environment of $\mathrm{Ti}^{3+}$ ions produced under $\beta$-irradiation in Ti-doped $\mathrm{SiO}_{2}$ $-\mathrm{Na}_{2} \mathrm{O}-\mathrm{TiO}_{2}$ glasses. We conclude to the existence of three different $\mathrm{Ti}^{3+} \mathrm{EPR}$ sites, denoted $s_{l}, s_{\| /}$and $s_{\| I /}$. The first one, $s_{l}\left(g_{/ /}=1.970\right.$ and $\left.g_{\perp}=1.939\right)$, is associated to $\mathrm{a}^{[\mathrm{VII}} \mathrm{Ti}^{3+}$ in an octahedron of oxygens and is observed only when the $[\mathrm{Na}][\mathrm{Ti}]$ ratio of the glass is higher or equal to 68 and the integrated dose less than $1 \times 10^{9}$ Gy. The second site, $s_{\|}\left(g_{1}=1.868, g_{2}=1.904, g_{3}=1.965\right)$ is attributed to a $\mathrm{Ti}^{3+}$ ion in a trigonal bi-pyramid environment. The last one, $s_{I I I}\left(\mathrm{~g}_{1}=\right.$ $\left.1.763, g_{2}=1.863, g_{3}=1.936\right)$, is dominant ( $80 \%$ of the total amount of observed $\mathrm{Ti}^{3+}$ ions) and corresponds to a ${ }^{\left[{ }^{[} \mathrm{T}\right.} \mathrm{Ti}^{3+}$ ion in a square pyramid of oxygens. The $s_{I I}$ and $s_{I I I}$ sites are observed for all values of the $[\mathrm{Na}] /[\mathrm{Ti}]$ ratio.

\section{Acknowledgements}

We sincerely thanks T. Pouthier and V. Metayer (LSI, Ecole Polytechnique, France) for their kind help during synthesize irradiation and study of the samples.

\section{References}

[1] N. Ollier, P. Lombard, F. Farges, B. Boizot, Journal of Non Crystalline Solids, 354, 480 (2008).

[2] E. Malchukova, B. Boizot, G. Petite, D. Ghaleb, Journal of Non-Crystalline Solids 353, 2397 (2007).

[3] B. Boizot, F.Y. Olivier, G. Petite, D. Ghaleb, Nuclear Instrument and Methods in Physics Research B 266, 2966 (2008). 
[4] F.Y. Olivier, B. Boizot, D. Ghaleb, G. Petite, Journal of Non-Crystalline Solids 351, 1061 (2005).

[5] B. Boizot, G. Petite, D. Ghaleb and G. Calas. Nuclear Instrument and Methods in Physics Research B 141, 580 (1998).

[6] N. Ollier, B. Champagnon, B. Boizot, Y. Guyot, G. Panczer and B. Padlyak, Journal of Non Crystalline Solids 323, 200 (2003).

[7] B. Boizot, N. Ollier, F. Olivier, G. Petite, D. Ghaleb and E. Malchukova. Nuclear Instrument and Methods in Physics Research B 240, 146 (2005).

[8] B. Boizot, G. Petite, D. Ghaleb, B. Reynard and G. Calas, Journal of Non Crystalline Solids 243, 268 (1999).

[9] N. Ollier, B. Boizot, R. Reynard, D. Ghaleb and G. Petite, Journal of Nuclear Materials 340, 209 (2005).

[10] B. Boizot, G. Petite, D. Ghaleb, N. Pellerin, F. Fayon, B. Reynard and G. Calas, Nuclear Instruments and Methods in Physics Research B 166, 500 (2000).

[11] D. Neuville, L. Cormier, B. Boizot, A. Flank, Journal of Non Crystalline Solids, 323, 207 (2003).

[12] R. Greegor, F. Lytle, D. Sandstrom, J. Wong and P. Schultz, Journal of Non Crystalline Solids 55, 27 (1983).

[13] F. Farges, G. Brown, E. Navrotsky, H. Gan and J. Rehr, Geochimica et Cosmoschimica Acta 60, 3039 (1996).

[14] G. Henderson and J. St - Amour, Chemical Geology 213, 31 (2004).

[15] G. Henderson and M. Fleet, Journal of Non Crystalline Solids 211, 214 (1997).

[16] F. Farges, G. Brown and J. Rehr, Geochimica and Cosmochimica Acta 60, 3023 (1996).

[17] F. Farges, Journal of Non Crystalline Solids 244, 25 (1999).

[18] G. Henderson, X. Liu and M. Fleet, Mineralogical Magazine 67, 597 (2003).

[19] B. Mysen and D. Neuville Geochimica and Cosmochimica Acta 59(2), 325 (1995).

[20] G. Henderson, The Canadian Mineralogist 33, 399 (1995).

[21] F. Farges. American Mineralogist 82, 36 (1997).

[22] A. Abragam and B. Bleaney. Electron Paramagnetic Resonance of transition ions. Clarendon Press, 1970.

[23] G. Morin and D. Bonnin. Journal of Magnetic Resonance 136, 176 (1999).

[24] A. Weil, J. Bolton and J. Wertz. Electron Paramagnetic Resonance. Wiley Interscience, 1994. 
[25] N. Iwamoto, H. Hidaka and Y. Makino. Journal of Non-Crystalline Solids 58, 131 (1983).

[26] S. Arafa and F. Assabghy. Journal of Applied Physics 45(12) 5269 (1974).

[27] C. Cailleteau, C. Weigel, A. Ledieu, P. Barboux and F. Devreux. Journal of NonCrystalline solids 354, 117 (2008).

[28] B. Bunker. Journal of Non-Crystalline Solids 179, 300 (1994).

[29] H. Bohm and G. Bayer, Journal of Non Crystalline Solids, 31, 2125 (1970). [30] V. Laguta, M. Glinchuk, I. Bykov and Y. Maksimenko, Physical Review B 54, 12353 (1996).

[31] Y. Kim and P. Bray, The Journal of Chemical Physics 53, 716 (1970).

[32] S. Arafa and A. Bishay, Physics and Chemistry of Glasses 11, 75 (1970).

[33] M. Nolan, S. Eliott, J. Mulley, R. Benett, M. Basham and P. Mulheran, Physical Review B 77, 235424 (2008). 
Figure captions

Figure 1. X-band EPR spectra recorded at $20 \mathrm{~K}$ of $\mathrm{SiO}_{2}-\mathrm{Na}_{2} \mathrm{O}-\mathrm{TiO}_{2}$ glasses $\beta$ irradiated at $3.23 \times 10^{7} \mathrm{~Gy}$. The $g$ values indicated in the figures correspond to the minima or maxima of the different $\mathrm{Ti}^{3+} \mathrm{EPR}$ lines.

Figure 2. X-band EPR spectra recorded at $20 \mathrm{~K}$ of the S20 and S80 samples nonirradiated and $\beta$-irradiated at different doses between $3.24 \times 10^{6}$ and $1.68 \times 10^{9} \mathrm{~Gy}$. The $g$ values indicated in the figures correspond to the minima or maxima of the different $\mathrm{Ti}^{3+} \mathrm{EPR}$ lines.

Figure 3. X-band EPR spectra at $20 \mathrm{~K}$ of the $\mathrm{S} 20$ and $\mathrm{S} 80$ samples recorded just after ("initial") and 165 after $\beta$-irradiation at $3.23 \times 10^{7} \mathrm{~Gy}$. The $g$ values indicated in the figures correspond to the minima or maxima of the different $\mathrm{Ti}^{3+} \mathrm{EPR}$ lines.

Figure 4. Experimental, simulated and components of the X-band EPR spectrum of the $\mathrm{S} 80$ sample $\beta$-irradiated to $3.24 \times 10^{7}$ Gy.

Figure 5. Mean proportion of the number of $\mathrm{Ti}^{3+}$ ions in the $s_{\mid}, s_{||}$and $s_{|l|}$ sites identified in $\beta$-irradiated titanium doped silicate glasses as the function of the dose integrated. 
Tables

\begin{tabular}{|c|cccc|c|}
\hline Sample & {$\left[\mathrm{SiO}_{2}\right]$} & {$\left[\mathrm{Na}_{2} \mathrm{O}\right]$} & {$\left[\mathrm{TiO}_{2}\right]$} & {$[\mathrm{Na}] /[\mathrm{Ti}]$} & Ref. \\
\hline $\mathrm{S} 10$ & 76 & 20 & 4 & 10 & {$[21]$} \\
$\mathrm{S} 20$ & 78 & 20 & 2 & 20 & {$[21]$} \\
$\mathrm{S} 40$ & 79 & 20 & 1 & 40 & - \\
$\mathrm{S} 68$ & 65 & 34 & 1 & 68 & {$[19]$} \\
$\mathrm{S} 80$ & 59 & 40 & 1 & 80 & - \\
\hline
\end{tabular}

Table 1. Samples composition. All quantities are in mol\%.

\begin{tabular}{|c|c|c|c|c|c|c|}
\hline Site & $g_{1}$ & $g_{2}$ & $g_{3}$ & $s_{0}$ & $s_{1}$ & $s_{2}$ \\
\hline$s_{I}$ & 1.939 & \multicolumn{2}{|c|}{1.970} & 0.00282 & 0 & 0 \\
\hline$s_{\|}$ & 1.868 & 1.904 & 1.965 & 0.00363 & 0.03107 & 0.02088 \\
\hline$s_{I I I}$ & 1.763 & 1.863 & 1.936 & 0.00514 & 0.13127 & 0.06273 \\
\hline
\end{tabular}

Table 2. EPR parameters determined by simulation for the three $\mathrm{Ti}^{3+}$ sites observed in $\beta$-irradiated $\mathrm{SiO}_{2}-\mathrm{Na}_{2} \mathrm{O}-\mathrm{TiO}_{2}$ glasses. The $s_{0}, s_{1}$ and $s_{2}$ width are in $\mathrm{cm}^{-1}$. 
Figure 1

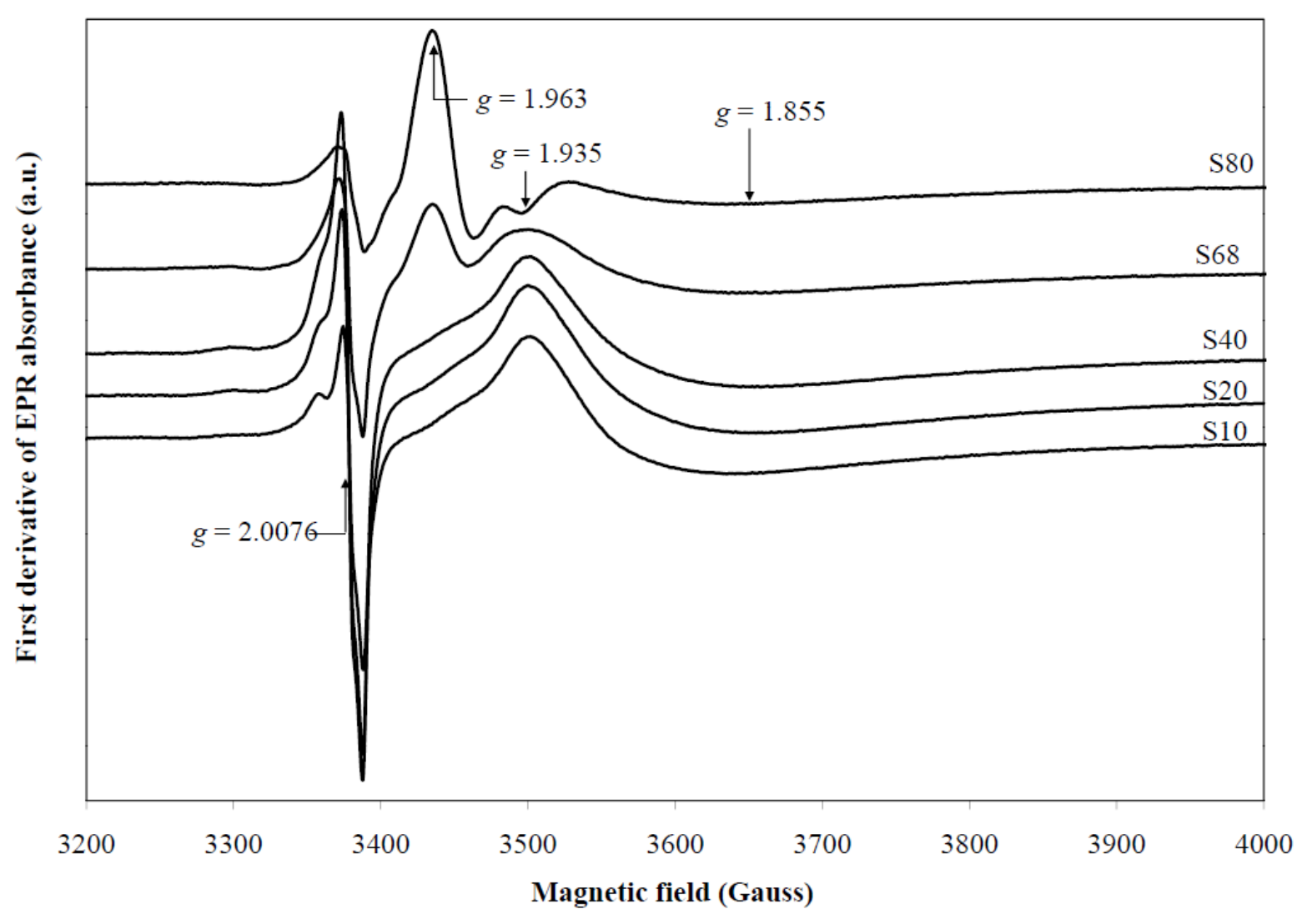


Figure 2
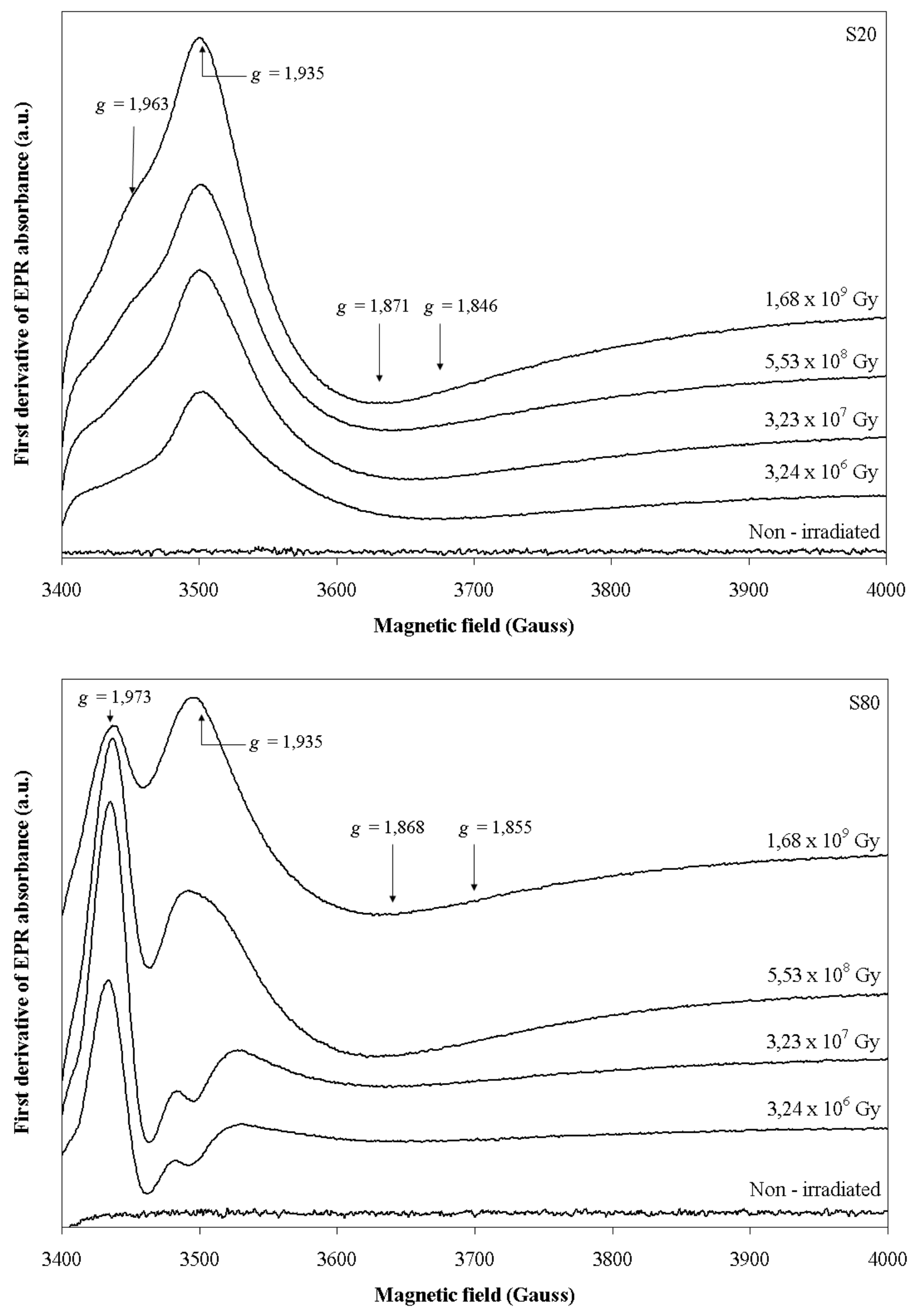
Figure 3

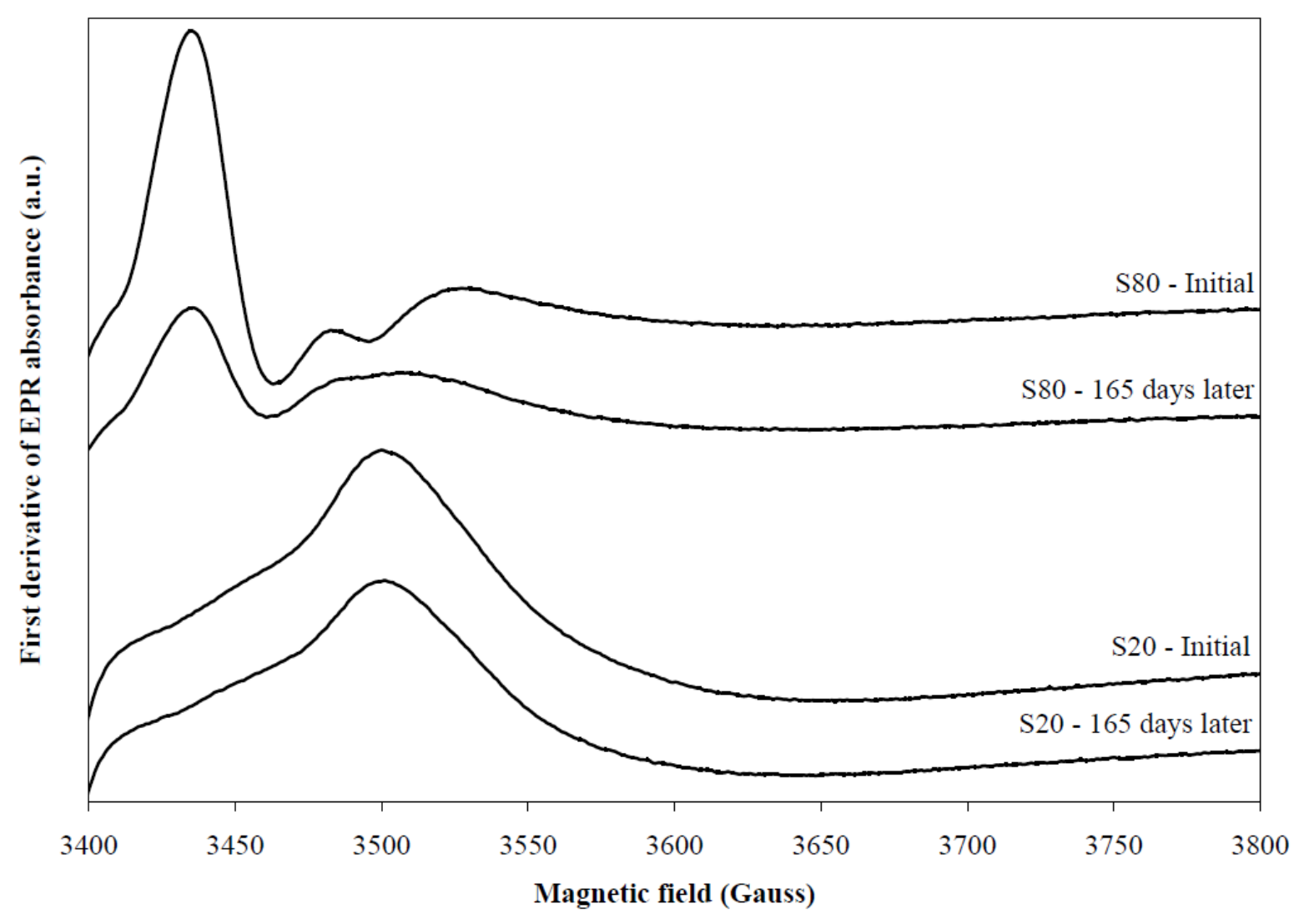


Figure 4

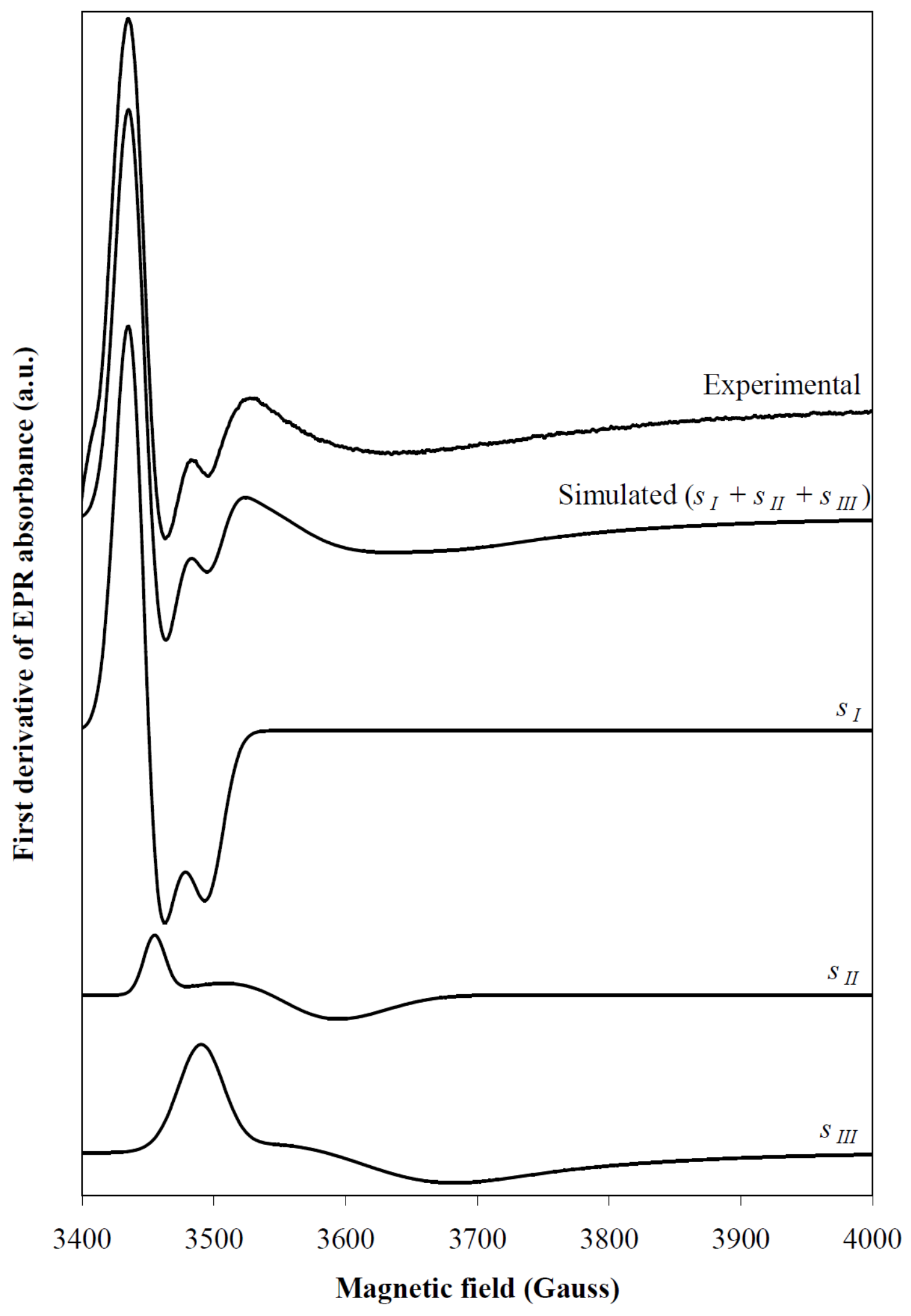


Figure 5

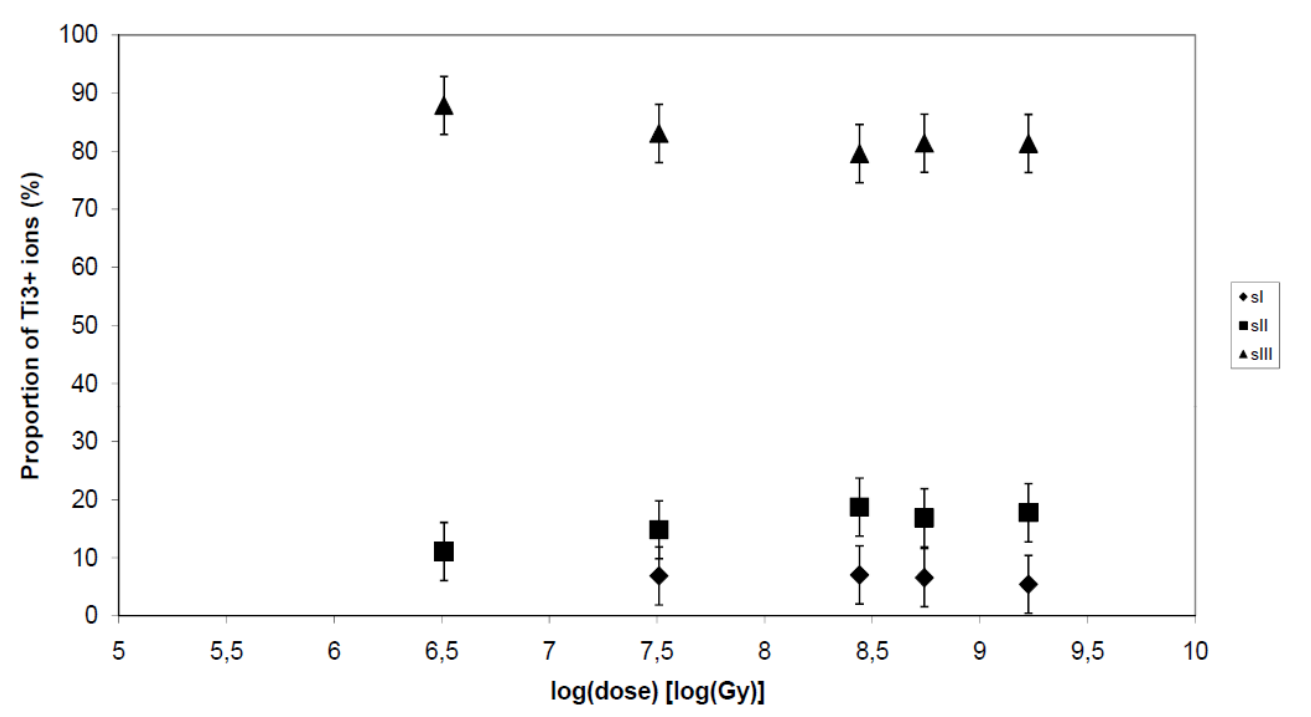

